\title{
UNIVERSALIDADE DO ACESSO E ACESSIBILIDADE NO QUOTIDIANO DA ATENÇÃO PRIMÁRIA: VIVÊNCIAS DE USUÁRIOS DO SUS
}

\author{
UNIVERSALITY OF ACCESS AND ACCESSIBILITY IN THE DAILY CARE OF PRIMARY CARE: SUS USER \\ EXPERIENCES
}

\section{UNIVERSALIDAD DEL ACCESO Y ACCESIBILIDAD EN EL COTIDIANO DE LA ATENCIÓN PRIMARIA: VIVENCIAS DE USUARIOS DEL SUS}

Lívia Silveira Silva ${ }^{1}$, Selma Maria da Fonseca Viegas², Leila Cristine do Nascimento ${ }^{3}$, Cássia Menezes ${ }^{4}$, Jéssica Rauane Teixeira Martins ${ }^{5}$, Tassiana Potrich 6 .

\section{RESUMO}

Objetivo: Compreender o acesso e a acessibilidade à saúde na perspectiva de usuários, em atendimento à demanda espontânea em unidades de Atenção Primária à Saúde (APS). Métodos: Estudo de Casos Múltiplos Holístico-qualitativo, fundamentado na Sociologia Compreensiva do Quotidiano com 60 participantes, em município de grande porte de Minas Gerais. Resultados: Revelam a Saúde como uma questão de luta no quotidiano da APS, destacando as dificuldades enfrentadas pelos usuários do Sistema Único de Saúde (SUS), no que concerne o acesso aos serviços, ações, exames e medicamentos. Denotam a desorganização administrativa e morosidade do Sistema, a questão política, a judicialização. A situação contemporânea do SUS foi questionada: o que precisa no SUS? Conclusão: A realidade vivenciada pelos usuários indica que ainda não foi alcançada a idealização de um Sistema universal, equânime e integral. Ademais, a pesquisa possibilitou reflexões de todos os atores envolvidos, usuários, profissionais de saúde e gestores, sobre o exercício da participação social no SUS e a formação de sujeitos proativos na tomada de decisões políticas para o cumprimento e vigor das legislações que implementam o SUS.

Descritores: Acesso aos serviços de saúde; Universalização da saúde; Atenção Primária à Saúde; Necessidades e demandas de serviços de saúde; Sistema Único de Saúde.

\section{ABSTRACT}

Objective: To understand the accessibility to health from the perspective of users in response to spontaneous demand in Primary Health Care (PHC) units. Methods: Holistic-qualitative Multiple Case Study based on Quotidian Comprehensive Sociology with 60 participants, in a large municipality of Minas Gerais. Results: They reveal Health as a matter of struggle in the daily life of PHC, highlighting the difficulties faced by users of the Brazilian Unified Health System (SUS) regarding access to services, actions, exams and medications. They denote the administrative disorganization and slowness of the System; political issues; and judicialization. The contemporary SUS situation was questioned: what do you need from SUS? Conclusion: The reality experienced by users indicates that the idealization of a universal, equitable and integral system has not yet been achieved. Furthermore, the research allowed reflections of all users, health professionals and managers on the exercise of social participation in SUS and the formation of proactive subjects in making political decisions for the compliance and vigor of the laws that implement SUS.

Descriptors: Health services accessibility; Universalization of health; Primary Health Care; Health needs and demands; Unified Health System.

\section{RESUMEN}

Objetivo: Comprender el acceso y la accesibilidad a la salud en la perspectiva de los usuarios, en respuesta a la demanda espontânea en unidades de Atención Primaria a la Salud (APS). Métodos: Estudio de Casos Múltiples Holístico-cualitativo, fundamentado em la Sociología Comprensiva del Quotidiano con 60 participantes, en municipio de gran porte de Minas Gerais. Resultados: Revelan la Salud como una cuestión de lucha em el cotidiano de la APS, destacando lãs dificultades enfrentadas por los usuarios del Sistema Único de Salud (SUS) em lo que concierne al acceso a los servicios, acciones, exámenes y medicamentos. Denota la desorganización administrativa y la morosidad del sistema; la cuestión política; la judicialización. La situación contemporânea del SUS fue cuestionada: ¿qué necessita em el SUS? Conclusión: La realidad experimentada por los usuarios indica que la idealización de un sistema universal, equitativo e integral aún no se ha logrado. Además, la investigación permitió reflexionar sobre todos los actores involucrados, usuarios, profesionales de la salud y gerentes, sobre el ejercicio de la participación social en el SUS y la formación de sujetos proactivos en la toma de decisiones políticas para el cumplimiento y el vigor de las leyes que implementan el SUS.

Descriptores: Accesibilidad a los servicios de salud; Universalización de la Salud; Atención Primaria de Salud; Necesidades y demandas de servicios de salud; Sistema Único de Salud.

${ }^{1}$ Enfermeira. Mestranda do Programa de Pós-Graduação Mestrado Acadêmico em Enfermagem da Universidade Federal de São João del-Rei (UFSJ). ${ }^{2}$ Doutora e Pós-Doutora em Enfermagem. Docente Adjunta da UFSJ. ${ }^{3}$ Enfermeira. Mestranda do Programa de Pós-Graduação Mestrado Acadêmico em Enfermagem da UFSJ. ${ }^{4}$ Enfermeira pela UFSJ. ${ }^{5}$ Mestre pelo Programa de Pós-Graduação Mestrado Acadêmico em Enfermagem da UFSJ. ${ }^{6}$ Doutora em Enfermagem. Docente Adjunta da Universidade Federal da Fronteira Sul- Campus Chapecó, SC, Brasil. 


\section{INTRODUÇÃO}

A Constituição da República Federativa do Brasil, de 1988, instituiu o Sistema Único de Saúde (SUS), para assegurar a garantia da universalidade do acesso à saúde como dever do Estado, indiscutivelmente, a maior conquista social da população brasileira. Contudo, passados mais de 30 anos da implantação do SUS, persistem importantes desafios para garantia do direito à saúde no país ${ }^{(1)}$.

Considerando a materialização da saúde como direito que é de todos ${ }^{(2)}$, e a construção do Sistema de acesso universal, a reorganização da Atenção Primária à Saúde no Brasil, se deu com a criação do Programa Saúde da Família (PSF), em 1994, incorporando a experiência anterior do Programa de Agentes Comunitários, iniciada em 1991, transformado em uma estratégia de abrangência nacional pela Política Nacional de Atenção Básica (PNAB), em 2006 ${ }^{(3)}$, a Estratégia Saúde da Família (ESF).

Em 2017, a PNAB é revisada pela Portaria $\mathrm{n}^{\circ}$ 2436, de 21 de setembro de 2017, que considera os termos Atenção Básica e Atenção Primária à Saúde como termos equivalentes, de forma a associar a ambos os mesmos princípios e diretrizes desse nível de atenção à saúde. Assim, a APS é definida como "o conjunto de ações de saúde individuais, familiares e coletivas que envolvem promoção, prevenção, proteção, diagnóstico, tratamento, reabilitação, redução de danos, cuidados paliativos e vigilância em saúde, desenvolvida por meio de práticas de cuidado integrado e gestão qualificada, realizada com equipe multiprofissional e dirigida à população em território definido, sobre as quais as equipes assumem responsabilidade sanitária"(4).

A APS/ESF como porta preferencial do usuário e família, está presente em 5.477 municípios dos 5.570 existentes no Brasil(5), oferta a todos os cidadãos ações e serviços próprios e essenciais, sem qualquer exclusão, com acesso universal, integral, equânime, adaptados às necessidades de saúde de seus indivíduosfamílias-comunidade em suas múltiplas realidades, considerando os determinantes e condicionantes de saúde. É centro de comunicação da Rede de Atenção à Saúde (RAS), coordenadora do cuidado e ordenadora das ações e serviços disponibilizados na RAS ${ }^{(4)}$.

Mas, "não basta apreender as condições de vida e necessidades do usuário e das famílias. É necessário que a população tenha acesso a um Sistema com ações integrais como direito"(2).
Acesso à saúde envolve a disponibilidade de recursos e serviços, a aceitabilidade, que é um fator motivador da preferência pelo serviço por propiciar o alcance de seus objetivos, isto é, a resposta resolutiva à necessidade, contemplando a acessibilidade ${ }^{(6)}$.

Apesar de a APS constituir-se uma porta de entrada no Sistema, a prioritária, o atendimento, em sua maioria, decorre da demanda espontânea, a partir de necessidades individuais dos usuários, uma vez que os interesses são, geralmente, por consultas médicas, encaminhamentos às especialidades e distribuição de medicamentos. Na demanda espontânea, o indivíduo procura os serviços de saúde de forma inesperada, objetivando o acesso e resolução do que procura. "Acredita-se que ao possibilitar livre acesso da demanda espontânea à APS, especialmente no caso das doenças crônicas que necessitam de tratamento contínuo, a efetividade do cuidado e o vínculo poderão ser comprometidos, pois os usuários recorrem às unidades de APS visando a um atendimento pontual, confrontando o controle de situações agudas de adoecimento com as estratégias de promoção da saúde nas doenças crônicas, propostas por esse nível de atenção"(7).

Com a expansão da APS/ESF, ao longo desses últimos 30 anos do SUS, ampliou-se o acesso às consultas médicas e a redução das internações para condições sensíveis a esse âmbito de atenção. Contudo, "apesar dos avanços na cobertura populacional, ainda permanecem desafios significativos à continuidade do SUS e à melhoria da qualidade do cuidado: oferta e qualidade dos serviços, subfinanciamento e relação público-privado"(8).

Temos um SUS público, com financiamento insuficiente e inadequado às suas atribuições. "Apesar de o SUS ser responsável exclusivo pelo atendimento de $75 \%$ da população, o faz com cerca de $46 \%$ dos recursos do setor"(9). Ademais, toda a população é assistida pelo SUS, mesmo os usuários que, na assistência, preferem recorrer aos planos de saúde, pois o SUS não desenvolve somente ações relacionadas à assistência à saúde, mas também se ressalta a vigilância sanitária, a vigilância epidemiológica, vacinação, dentre outras $^{(10)}$.

Ao abordar o acesso e acessibilidade do usuário no quotidiano da APS, pode-se entender o quotidiano como a "maneira de viver no dia a dia, expresso por suas interações, crenças, valores, símbolos, significados, imagens e imaginário que vão delineando seu processo de viver pontuando 
seu ciclo vital"(11). Todavia, esse "percurso pelo ciclo vital tem uma determinada cadência que caracteriza sua maneira de viver influenciada, tanto pelo dever ser quanto pelas necessidades e desejos do dia a dia, que se denomina como ritmo de vida e do viver. Assim, o cotidiano não se mostra apenas como cenário, mas, sobretudo, revela tanto as cenas do viver como do conviver"(12). Destarte, "o cotidiano é o objeto de estudo nos diferentes cenários da pesquisa em Enfermagem e Saúde, não apenas como sinônimo de dia a dia, mas também, como expressão de uma maneira de viver em um determinado

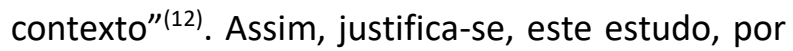
considerar a universalidade do acesso e acessibilidade nas vivências cotidianas de usuários na APS.

Considerando o cotidiano da APS frente à demanda espontânea dos usuários, questiona-se: Como se estabelece o acesso e acessibilidade à saúde, na perspectiva dos usuários em atendimento na demanda espontânea no cotidiano da APS?

Neste artigo, objetivou-se compreender o acesso e a acessibilidade à saúde na perspectiva dos usuários, em atendimento à demanda espontânea em unidades de APS.

\section{MÉTODOS}

Trata-se de um Estudo de Casos Múltiplos Holístico-qualitativo ${ }^{(13)}$, fundamentado na Sociologia Compreensiva do Quotidiano de Michel Maffesoli ${ }^{(14)}$.

O Estudo de Casos Múltiplos Holístico possibilita a investigação social da realidade empírica de um contexto de vida real, preservando a totalidade e o caráter unitário do fenômeno estudado ${ }^{(13)}$. Contemplaram o cenário, deste estudo, cinco unidades de APS Tradicional, sem equipes da ESF, e cinco unidades com equipes da ESF, obedeceram-se ao critério de coleta de dados até a saturação dos dados, definido por sorteio aleatório das 43 unidades de APS da região urbana de município de grande porte de Minas Gerais, Brasil (32 de ESF e 11 da APS Tradicional). A saturação dos dados ocorreu no 60 ำ participante entrevistado, por replicação literal| ${ }^{(13)}$. Assim, trata-se de dois casos que contemplam realidades diferentes pela forma de composição das equipes e organização do trabalho quotidiano no contexto da APS. Cada caso versou em uma investigação empírica e "completa"(13) do fenômeno contemporâneo dentro do contexto da vida real, no qual buscaram-se evidências convergentes ou divergentes, com respeito aos fatos e às conclusões para os casos $^{(13)}$. Este estudo por ser holístico teve como unidade única de análise, para os dois casos: "acesso, acessibilidade e demanda espontânea no quotidiano da APS".

No município, cenário do estudo, são contabilizados 64 estabelecimentos públicos de saúde com prestação de serviços em 11 Unidades de APS Tradicional, 32 equipes da ESF, 01 Policlínica, 01 Unidade de Pronto-Atendimento Regional (UPA), 01 Centro de Atenção Psicossocial (CAPS), que conta com os serviços de Urgência e Emergência Psiquiátrica, Ambulatório Psiquiátrico e 01 CAPS AD III, 07 farmácias para dispensação de medicamentos básicos, 01 unidade de Vigilância em Saúde, 01 Central de Imunização, 01 Centro Regional de Reabilitação, 01 Serviço Especializado de Odontologia, 03 serviços auxiliares de diagnose e terapia, e Serviço de Atendimento Móvel de Urgência (SAMU). Outros estabelecimentos privados/filantrópicos participam de forma complementar ao SUS, entre eles 03 hospitais e 16 serviços especializados (Notas de Campo- NC).

A Sociologia Compreensiva do
Quotidiano $^{(14)}$ abaliza, neste estudo, a
compreensão e a interpretação do fenômeno contemporâneo acesso e acessibilidade, sob a ótica do usuário, frente às práticas cotidianas exercidas no contexto da APS, no atendimento à demanda espontânea, considerando os serviços e ações ofertados no SUS versus as necessidades de cada um que procura por atendimento. Assim, ocupa-se em buscar o conhecimento "por meio de uma visão interna" ${ }^{(14)}$, pois "não existe uma única realidade, mas sim, maneiras diferentes de concebê-las/conhecê-las"(14). "Esse referencial é conveniente para descrever o contexto desta ou daquela situação social onde somos parte integrante (e interessada) daquilo que desejamos falar"(14).

Os participantes desta pesquisa foram os usuários que se encontravam nas 10 unidades de APS/ESF para acolhimento à demanda espontânea, cujas participações foram voluntárias, em um total de 60 participantes. A saturação se deu em cada caso, até fechar a amostra, e obter dados significantes para a análise e a interpretação dos casos múltiplos holístico, ocorrida pela replicação literal que prevê resultados semelhantes, e não a amostragem. Ou seja, após revelar uma descoberta significativa no primeiro caso, objetivo imediato desta pesquisa foi replicar essa descoberta conduzindo o segundo caso. A lógica da replicação é análoga à usada nos 
experimentos múltiplos que após a descoberta de resultado significativo por meio de um experimento único, busca-se replicar este achado conduzindo outros experimentos ${ }^{(13)}$.

Como critério de inclusão, adotou-se: usuários cadastrados pelas equipes da ESF ou pelas unidades da APS tradicionais do município, após atendimento pela equipe na demanda espontânea, e maiores de 18 anos de idade. Como critério de exclusão, estabeleceu-se a pessoa incapacitada de responder por seus atos.

A coleta de dados ocorreu em 2016, teve-se como fontes de evidências a entrevista aberta intensiva e individual com roteiro semiestruturado; registros em notas de campo (NC) direcionadas para os procedimentos operacionais da pesquisa, descrevendo características do município, das equipes da APS Tradicional e das equipes ESF; realizadas após cada coleta de dados.

A priori, foi realizado um pré-teste do roteiro de entrevista, sob a coordenação da pesquisadora responsável. A entrevista foi realizada, individualmente, após o atendimento do usuário em demanda espontânea, em sala privada e segura cedida pela Instituição de Saúde. Foi apresentado o termo de consentimento sendo esclarecido o objetivo, a temática do estudo e a participação voluntária. Dos usuários abordados, 10 se recusaram a participar da pesquisa. As entrevistas tiveram duração média de 20 minutos, foram gravadas em meio digital e transcritas na íntegra.

Para a análise dos dados, utilizou-se da Análise de Conteúdo Temática, segundo as fases: pré-análise, exploração do material, tratamento dos resultados, inferência e interpretação(15), integrando-se aos pressupostos da Sociologia Compreensiva do Quotidiano ${ }^{(14)}$, ao considerar a noção de acesso e acessibilidade à saúde na perspectiva dos usuários, em atendimento à demanda espontânea em unidades de APS. De acordo com Maffesoli ${ }^{(14)}$, noção é mais generosa do que a palavra conceito, e "o método compreensivo permite uma abordagem indutiva"(14), sendo que o nosso conhecimento comum é o que nos prepara para a vida [...] Com isso, a sociologia que trabalha com socialidade, imaginário ou quotidiano não deve mais produzir conteúdos, mas sim operar como ponto de vista $^{(14)}$.

A pesquisa foi desenvolvida, segundo a Resolução do Conselho Nacional de Saúde $n^{\circ} 466$, de 12 de dezembro de 2012. A coleta de dados iniciou-se, após a aprovação do projeto sob o parecer de no 1.251 .730 e CAAE 48043315.2.0000.5545. Cabe ressaltar que foi mantido o anonimato dos participantes da pesquisa, por meio da identificação alfanumérica, na qual a letra " $E$ " identifica a palavra entrevistado, com numeração consecutiva, conforme sequência das entrevistas.

\section{RESULTADOS}

A apresentação dos resultados,
considerando a categoria temática "Universalidade do acesso e acessibilidade no quotidiano da atenção primária: vivências de usuários do SUS" está apresentada em duas subcategorias: "Saúde, uma questão de luta?" e "No SUS a acessibilidade é difícil, mas o que o Plano de Saúde assegura?"

A subcategoria "Saúde, uma questão de luta?" leva a considerar que o Movimento da Reforma Sanitária foi a maior e a mais importante conquista política e social do povo brasileiro. Tal conquista, entretanto, não esteve livre de disputas que, mesmo à época e até hoje, aos 30 anos de SUS, imprimem significativas buscas à plena efetivação do direito universal à saúde. Assim, vivemos a dificuldade de acesso a uma atenção integral, pois até o básico falta, segundo o relato: "Geralmente, eu acho que eles ludibriam as pessoas, entendeu? Porque eles falam que tem que levar para a secretaria de saúde (o encaminhamento). [...] Outra hora não tem médico, tem que esperar contratar médico. Falar que não vai ter jeito de atender eles não falam! Só que, se você for esperar, a pessoa pode até chegar a perder a vida, não é? Porque já aconteceu muito. [...] E o que precisa no SUS que é o essencial, o básico, não tem!" $\left(E_{1}\right)$

Dentre as demandas espontâneas, os participantes inferiram sobre a transcrição de receitas oriundas da APS, pelo vencimento para renovação e das prescritas no setor privado/suplementar $\left(\mathrm{E}_{1}, \mathrm{E}_{2}, \mathrm{E}_{3}, \mathrm{E}_{31}, \mathrm{E}_{33}, \mathrm{E}_{44}, \mathrm{E}_{48}\right)$.

Segundo informações registradas em notas de campo, mesmo tendo plano de saúde ou consultas no setor privado, as medicações, em sua maioria, são adquiridas no setor público. Assim, sem a transcrição ou renovação das prescrições, o acesso aos medicamentos fica impedido:

"Estou com as receitas para transcrever e ver se eu consigo pegar os remédios pelo SUS, marcou a consulta só para daqui a dois meses, vou ter que comprar os remédios caros [...] Mas 
também não tem nada na farmacinha não, só tem Prednisona e Metiformina" $\left(E_{3}\right)$.

"Hoje eu vim consultar, porque estou com um problema de hemorroida [...] Só que me falaram que eu não podia consultar aqui. Ontem eu fui ao (médico) particular, para tentar pegar uma receita, aí ele me falou que não ia me atender, que eu deveria procurar um especialista" $\left(\mathrm{E}_{33}\right)$.

"O que falta, às vezes, são alguns remédios, mas está faltando em todo lugar, não é?" ( $\left.E_{44}\right)$.

A judicialização foi contemplada:

"Todo mês eu venho, porque o meu marido tem que fazer controle, ele teve que tomar um remédio e eu tive que entrar na justiça, na defensoria para conseguir o medicamento, sabe? Porque ficava muito caro [...] na faixa de uns 70 mil reais o medicamento. Aí entrei no Ministério Público, consegui o remédio, entrei em abril de 2015, correndo atrás, e em junho de 2015 ele tomou" $\left(E_{3}\right)$.

A falta de acesso aos exames ou a longa espera, e o porquê da espera foi apontado pelos participantes $\left(E_{4}, E_{9}, E_{17}, E_{25}, E_{51}\right)$. O longo período de espera é delegado à precária administração, uma vez que altos impostos são atribuídos aos cidadãos:

"Mas, é uma luta, tem exame meu que já está aqui há cinco anos! [...] Eu preciso de um ultrassom de urgência e o pedido é de consulta particular, tive que pagar a consulta. Eu já fiz o levantamento e não tenho condição de fazer, porque meu marido não está trabalhando, então vou ter que esperar, diz ela que é um ano, mais ou menos" $\left(E_{51}\right)$.

"Pediram ultrassom para minha Mãe e já tem uns nove meses, mas ela não conseguiu fazer. Então assim, você fica com aquela preocupação, a pessoa vai se frustrando e deixa até de se cuidar, porque não consegue um exame! Agora exame de sangue e de urina esses aí até têm, o problema são esses exames mais complicados, e no particular realmente é caro!" $\left(E_{17}\right)$

"O que me incomoda é a demora não só para mim, mas para muita gente. Meu filho faz exames e eles demoram demais [...] ele pode acabar até indo a óbito por causa da demora. O pai dele morreu de câncer porque a demora foi tão grande, infelizmente o câncer tomou conta do corpo dele. E essa demora é culpa dos governantes que são péssimos administradores, porque esse País tem dinheiro, o povo paga muito imposto" $\left(E_{25}\right)$.
Foi apontada a facilidade de acesso em outra realidade:

"Eu não sou daqui, lá na minha cidade natal eu nunca tive tanta dificuldade, é uma cidade bem menor, claro que para alguma consulta mais específica ou um exame, a gente tem que ir para outra localidade, mais lá eles conseguem o encaminhamento rápido. Aqui, sei que não é só aqui, região metropolitana toda está assim, com muita dificuldade nessa questão de saúde" $\left(E_{17}\right)$.

Durante o período de permanência das pesquisadoras, na recepção da Unidade de Saúde para aguardar o usuário ser atendido em livre demanda e, posteriormente, abordá-lo para possível entrevista, as necessidades demandadas se voltaram para: o encaminhamento ao especialista, solicitar ou reclamar o não agendamento; a transcrição de prescrições e exames solicitados em serviços privados ou suplementares; a reclamação da falta de medicamento; e de acesso às consultas médicas; corroborando com os dados das entrevistas (NC).

A subcategoria, No SUS a acessibilidade é difícil, mas o que o Plano de Saúde assegura? Corresponde à referência dos usuários da APS aos planos de saúde $\left(E_{11}, E_{22}, E_{48}, E_{52}, E_{60}\right)$. Os usuários mantêm plano de saúde para agilizarem algumas ações e consultas, mas sempre recorrem ao serviço público pelas limitações do acesso, e pela coparticipação onerar o orçamento da família, no valor a ser pago para consultas, exames ou outros procedimentos (NC).

"Porque convênio de saúde é para quê? Para assegurar o quê? Ele não assegura a saúde. $O$ que assegura saúde é postura de vida, alimentação boa, não passar raiva, é ter consciência para se cuidar" $\left(E_{22}\right)$.

"Eu tenho plano de saúde, mas quase não uso, só pago para casos de emergência. Não utilizo muito não, só no caso de fazer um exame para andar mais rápido, aí venho e mostro aqui no posto" ( $\left.\mathrm{E}_{48}\right)$.

"Olha, eu tinha plano mais cortei, estava muito caro, muito ruim, a gente ia mexer e quando precisava dele não tinha, não funcionava. Eu fiquei internada 20 dias no Hospital, eu tinha plano e fiquei no corredor, bem dizer, eu joguei sete mil reais fora, não adiantou nada" $\left(E_{52}\right)$.

Foi perceptível uma relação de maior vínculo com a equipe de saúde, quando os usuários têm como referência a equipe da ESF, demonstrando que mesmo estando em busca de atendimento no acolhimento da demanda espontânea, eles são acompanhados frente às 
condições crônicas ou em ações de prevenção de riscos e agravos (NC).

Saúde, uma questão de luta, destacou as dificuldades enfrentadas pelos usuários do SUS, no que concerne o acesso aos serviços, ações e medicamentos, sobretudo pelo revés vivenciado pelos usuários para a transcrição de receitas, agendamento de consultas e pela falta de disponibilidade de exames e medicamentos fornecidos pelo Sistema, configurando a assistência ao adoecimento. No cotidiano, essa busca e luta do usuário, pelo acesso à saúde se concretizou em todos os dias da coleta de dados (NC).

\section{DISCUSSÃO}

A acessibilidade aos serviços de saúde na APS é considerada como um dos principais problemas relacionados à assistência ${ }^{(16)}$. Esses problemas estão ligados à qualidade dos serviços, à eficácia da gestão, à dificuldade do acesso à consulta frente a uma demanda espontânea, que pode ser uma urgência, às filas para a realização do agendamento e longo tempo de espera, para atendimento na APS e para os encaminhamentos aos serviços de referência ${ }^{(16-17)}$. Tais achados assemelham-se aos discursos relatados, neste estudo, indicando que tais dificuldades estão sendo enfrentadas em diversos municípios brasileiros. Isso leva ao aumento da carência de assistência, ao descontentamento do usuário do SUS, que se vê, na maioria das vezes, entregue à própria sorte com poucos ou sem recursos para arcar gastos para tratamento ou recuperação da saúde.

Estudo realizado em Pernambuco, Brasil, evidencia fragilidades no que tange à coordenação do cuidado, à estrutura física, ao acolhimento com estratificação de risco, que têm rebatimentos negativos na resolubilidade da rede de APS ${ }^{(16)}$.

Como instituído, saúde é um direito de todos e dever do estado, cabendo ao poder público formular e implementar políticas públicas que resolvam e atendam os principais problemas de saúde da população de forma equânime e integral como assegura o SUS. Entretanto, para os usuários, deste estudo, saúde tornou-se uma questão de luta, afinal, várias são as dificuldades de acesso encontradas no dia a dia da APS.

Tendo em vista o subfinanciamento para a saúde pública ${ }^{(8)}$, é necessário que o indivíduo tenha persistência e lute para ser atendido no limiar da escassez de recursos no tratamento, principalmente em condições crônicas que podem trazer limitações importantes para sua qualidade de vida, caso o tratamento seja interrompido ou adiado.

A escassez de recursos foi atribuída, pelos participantes da pesquisa, à má administração política dos provimentos públicos, já que altos impostos são atribuídos aos cidadãos. Nessa perspectiva, em seus 30 anos, "o maior obstáculo e ameaça ao SUS vem sendo o subfinanciamento e privatização no âmbito da financeirização do orçamento público, e o maior desafio continua sendo político"(18).

Para Maffesoli(19), a sociedade é a representação de seu líder político, ele detém, em suas mãos, o controle e o poder de decisão de diversos âmbitos sociais. O político deve governar, por meio da gestão de paixões, que consiste em equilibrar, assegurar e proteger todos os elementos fundamentais de uma sociedade. Se tal equilíbrio não for alcançado, o político arcará com as consequências da efervescência social do levante das massas.

A universalização do acesso a todos os serviços de saúde, com equidade e integralidade, e a execução de ações de assistência terapêutica integral, inclusive a farmacêutica, são regulamentadas no SUS. Porém, estudo identifica insuficiência no acesso aos medicamentos e necessidade de efetiva garantia de acessibilidade ao tratamento com qualidade e resolutividade ${ }^{(20)}$.

Um estudo realizado, na região de Tigray, Ethiopia, identificou que a disponibilidade geral de medicamentos prioritários para salvar vidas de crianças $<5$ anos foi baixa, 34,1\%. Verificaram-se também todos os medicamentos disponibilizados nos setores público e privado, apresentando a disponibilidade de 41,9 e $31,5 \%$, respectivamente. A baixa disponibilidade e a acessibilidade à medicamentos genéricos prioritários, de menor preço, nos setores público e privado refletem uma falha na implementação da política de saúde sobre medicamentos prioritários para salvar vidas de crianças nesta região(21).

Os resultados, deste estudo, apontam a judicialização como alternativa para a obtenção do medicamento. A judicialização reflete a precariedade na administração da saúde pública, sobretudo a assistência farmacêutica, seja por fornecer um medicamento prescrito, seja por não contemplar nenhuma política pública para determinada doença. Porém, "o dilema enfrentado na prestação dos serviços de saúde e na judicialização é o de conciliar a distribuição equitativa dos recursos financeiros e não 
financeiros escassos e atender às demandas da sociedade, que são infinitas, o que implica em buscar o equilíbrio entre o direito coletivo e o direito individual à saúde"(22).

No Brasil, $54 \%$ do gasto em saúde acontecem no setor privado, que atende a apenas $25 \%$ da população. "Mas os problemas do SUS persistem também, porque atores internacionais, a exemplo do Banco Mundial, nunca aceitaram o caráter universal e integral do sistema de saúde brasileiro. De tempos em tempos, divulgam documentos sobre o SUS, desqualificando-o e reafirmando a eficiência e a eficácia do setor privado. Na verdade, são agentes do capital que buscam ampliar os mercados consumidores, transformando a saúde em mercadoria"(9). "Como o SUS se destina, na prática, a maioria explorada da população, a consideração com os problemas de saúde e com a qualidade dos serviços de saúde, em grande medida, se assemelha ao descaso com que esse povo é tratado"(23).

Em, No SUS a acessibilidade é dificultada, mas o que o Plano de Saúde assegura? Foi declarada a percepção dos usuários sobre os planos de saúde privados, enfatizando que possuir plano de saúde no Brasil, nem sempre significa ter o direito à saúde, assegurado, porém facilita o acesso a alguns atendimentos e para a realização de exames.

Assim, "caberia à edição de lei ou norma que proibisse a utilização de recursos orçamentários, para financiar planos privados ou empresas. Essa proibição seria uma forma de induzir setores das elites econômicas e políticas a se aproximarem do SUS, além de aumentar o aporte financeiro ao SUS sem ampliação dos gastos públicos"(23).

Os sinais dos limites de acesso podem ser metaforizados pela falta, pois "a economia, os movimentos sociais, o imaginário e, até mesmo, a política estão sofrendo a ressaca de uma onda gigantesca cuja real amplitude ainda não se consegue avaliar. Mutação social que pede uma transmutação da linguagem: pós-modernidade é isso"(24). Em suma, aquilo que Durkheim chamava de "conformismo lógico" prefere continuar a gerenciar um instituído normal a um instituinte, possivelmente perigoso. É essa a dificuldade que existe para apreender-se a pós-modernidade nascente, dificuldade que consiste em reduzir um real denso e complexo a uma realidade mensurável. Compartimentando seu estudo em disciplinas separadas e que se excluem, chega-se a uma vida social da qual a própria vida está ausente ${ }^{(24)}$. Pois é frequente nas experiências vividas pelos usuários, deste estudo, em busca de acesso e acessibilidade na APS, em sua "história humana que a superfície das coisas ganha importância primordial”(24).

A saúde pode ser inferida como um impulso vital, que gera sensibilidade coletiva e necessita de uma ação política. Tendo em vista que, para atender às necessidades dos usuários, é preciso compreender e ter empatia por eles, como também organizar e priorizar o acesso e atendimento para acessibilidade aos mesmos.

Como uma porta de entrada prioritária e principal ponto de contato, a APS necessita ser resolutiva e fundamentar-se no vínculo e no cuidado longitudinal. Os resultados, deste estudo, demonstram que ainda não há um fluxo compatível com as demandas para a atenção de média e alta complexidade em saúde.

A "insuficiência da infraestrutura pública, a falta de planejamento ascendente, as dificuldades com a montagem de redes na regionalização e os impasses para a mudança dos modelos de atenção e das práticas de saúde também comprometem o acesso universal e igualitário às ações e serviços de saúde. Verifica-se a reprodução do modelo médico hegemônico, centrado mais na doença que na saúde, no tratamento que na prevenção ou promoção, no hospital e nos serviços especializados, e menos na comunidade, no território e na atenção primária”(25).

\section{CONSIDERAÇÕES FINAIS}

Como previsto na Constituição da República Federativa do Brasil, a saúde é um direito de todo cidadão. O Estado tem como dever assegurar o acesso facilitado aos serviços de saúde, com qualidade, em todas as camadas sociais brasileiras.

A qualidade da gestão administrativa e política no SUS, para acesso às ações e serviços, considerando a atenção usuário-centrada voltada para as necessidades de saúde de forma singulare equânime, levam à reflexão sobre a vigência ainda biomédica em livre demanda na APS, especificamente para grupos específicos, o que pode favorecer lacunas em várias áreas assistenciais, pensando no montante de usuários que dependem, exclusivamente, do Sistema Público brasileiro.

Vários são os problemas vivenciados pelos usuários no que concerne ao acesso e à acessibilidade aos serviços e ações em saúde. Dentre eles, destacam-se 0 acesso aos 
medicamentos, às consultas e aos exames. Tais problemas podem estar associados ao subfinanciamento do SUS, mas podem ter associação com os déficits na gestão desse Sistema, como também à cultura médica.

Os usuários buscam por acolhimento e acessibilidade, mas a escassez de recursos e ações, má administração e morosidade do Sistema dificultam o acesso e itinerário para alcançar a resolutividade frente às suas demandas, configurando a crescente demanda reprimida nos dois casos em estudo, nas unidades de APS tradicional e da ESF.

Ao buscar acesso universal aos serviços de saúde, a necessidade de recorrer à judicialização foi apontada. Alguns usuários buscam alternativas, contratando planos de saúde privados, mas acabam declarando as dificuldades enfrentadas para manter esse plano, frente à crise financeira vivenciada e à insatisfação mediante à falta de cobertura de algumas ações e procedimentos. Contudo, os usuários de planos de saúde declararam que recorrem ao Sistema Público de Saúde, pois nem sempre possuir plano de saúde garante acesso integral.

Historicamente, o SUS concedeu o direito à saúde e à voz ao povo brasileiro, mas na prática, isso se distancia, as pessoas pouco participam, apresentam-se submissas às decisões políticas, aos contratempos para o cumprimento e vigor das legislações que implementam esse Sistema.

A situação contemporânea do SUS, em seus 30 anos, na voz dos usuários, apresenta a restrição de acesso e da acessibilidade materializada, neste artigo, pelo questionamento: o que precisa no SUS? A realidade vivenciada indica que ainda não foi alcançada a idealização de um Sistema universal, equânime e integral.

Como contribuições para a área da Saúde, Enfermagem e público em geral, apresenta-se o conhecimento gerado pelas noções de usuários, atendidos em demanda espontânea na APS, sobre acesso e acessibilidade em saúde. Que essas noções possam possibilitar reflexões sobre essa temática, possibilitando respostas às necessidades de saúde da população e às dificuldades ainda vivenciadas no SUS, perante a acessibilidade, mesmo em concreta condição de expansão da ESF em municípios brasileiros.

\section{REFERÊNCIAS}

1- Miranda GMD, Mendes ACG, Silva ALA. O desafio da organização do Sistema Único de Saúde universal e resolutivo no pacto federativo brasileiro. Saúde Sociedade 2017;26(2):329-35. DOI: 10.1590/S0104-12902017168321

2- Viegas SMF, Penna CMM. As dimensões da integralidade no cuidado em saúde no cotidiano da Estratégia Saúde da Família no Vale do Jequitinhonha, MG, Brasil. Interface 2015;19(55):1089=100. DOI: 10.1590/180757622014.0275

3- Brasil. Portaria no 648/GM de 28 de março de 2006. Aprova a Política Nacional de Atenção Básica, estabelecendo a revisão de diretrizes e normas para a organização da Atenção Básica para o Programa Saúde da Família (PSF) e o Programa Agentes Comunitários de Saúde (PACS). Brasília: MS; 2006.

4- Brasil. Portaria no 2436 de 21 de setembro de 2017. Política Nacional de Atenção Básica, estabelecendo a revisão de diretrizes para a organização da Atenção Básica, no âmbito do Sistema Único de Saúde (SUS). Brasília: MS; 2017. 5- Brasil, Ministério da Saúde. Histórico de cobertura da saúde da família. Brasília: MS; 2018. 6- Scolari GAS, Rissardo LK, Baldissera VDA, Carreira L. Unidades de pronto atendimento e as dimensões de acesso à saúde do idoso. Rev Bras Enferm. 2018;71(2):811-7. DOI: 10.1590/00347167-2017-0440

7- Girão ALA, Freitas CHA. Usuários hipertensos na atenção primária à saúde: Acesso, vínculo e acolhimento à demanda espontânea. Rev Gaúcha Enferm. 2016;37(2):1-7. DOI: 10.1590/19831447.2016.02.60015

8- Viacava F, Oliveira RAD, Carvalho CC, Laguardia J, Bellido JG. SUS: Oferta, acesso e utilização de serviços de saúde nos últimos 30 anos. Ciênc Saúde Coletiva 2018;23(6):1751-62. DOI: 10.1590/1413-81232018236.06022018

9- Rizzotto MLF. A reafirmação da democracia e do direito universal à saúde em tempos de ultraneoliberalismo. Ciênc Saúde Coletiva 2018;23(6):1717-8. DOI: 10.1590/141381232018236.05682018

10- Freitas MAS, Araújo MRN. As Redes de Atenção à Saúde nos 30 anos do Sistema Único de Saúde: Histórias, propostas e desafios. Rev Bras Políticas Públicas 2018;8(3):15-34. DOI: 10.5102/rbpp.v8i3.5739

11- Nitschke RG, Rodrigues RSM, Silva APM, Rosa LM, Martins JT, Baldissera JLC, et al. Pressupostos teóricos e da sensibilidade na investigação sobre o quotidiano e a história da hemoterapia e hemorrede no sul do Brasil. Atas - Investigação Qualitativa em Saúde 2016 [citado em 7 abr 2019]; 2(1):1005-1014. Available in: 
https://proceedings.ciaiq.org/index.php/ciaiq201 6/article/view/848/834

12- Nitschke RG, Tholl AD, Potrich T, Silva KM, Michelin SR, Laureano DD. Contribuições do pensamento de Michel Maffesoli para pesquisa em enfermagem e saúde. Texto Contexto Enferm. 2017;26(4):1-12. DOI: 10.1590/010407072017003230017

13- Yin RK. Estudo de caso: Planejamento e métodos. 5a ed. Porto Alegre: Bookman; 2015.

14- Maffesoli M. O conhecimento comum: Introdução à sociologia compreensiva. Porto Alegre: Sulina; 2010.

15- Bardin L. Análise de conteúdo. São Paulo: Edições 70; 2011.

16- Ribeiro JP, Mamed SM, Souza MR, Souza MM, Rosso CFW. Acessibilidade aos serviços de saúde na Atenção Básica do Estado de Goiás. Rev Eletronica Enferm. 2015;17(3):1-11 DOI: 10.5216/ree.v17i3.29436

17- Gomide MFS, Pinto IC, Bulgarelli AF, Santos ALP, Gallardo MPS. A satisfação do usuário com a Atenção Primária à Saúde: uma análise do acesso e acolhimento. Interface 2018;22(65):387-98. DOI: 10.1590/1807-57622016.0633

18- Paim JS, Temporão JG, Penna GO, Santos NR, Pinto LF. Sistema Único de Saúde: 30 anos de luta! Cienc Saude Coletiva 2018;23(6):1-2. DOI: 10.1590/1413-81232018236.06612018

19- Maffesoli M. A transfiguração do político: A tribalização do mundo. Porto Alegre: Sulina; 2011. 20- Bandeira VAC, Schneider A, Schallemberger JB, Codinotti M, Pletsch MU, Colet CF. Avaliação da satisfação dos usuários das farmácias do sistema público de saúde. Rev Bras Promoç Saúde 2017;30(3):1-8.

DOI: 10.5020/18061230.2017.6193

21- Abrha S, Tadesse E, Atey TM, Molla F, Melkam W, Marsresha B, et al. Availability and affordability of priority lifesaving medicines for under-five children in health facilities of Tigray region, northern Ethiopia. BMC Pregnancy Childbirth 2018;18:2-9. DOI: 10.1186/s12884-018-2109

22- Lopes N, Frias L. A política pública de medicamentos e sua Judicialização. Cad Estudos Interdisciplinares 2014 [citado em 7 abr 2019]; 1(1):27-41. Available in: https://publicacoes.unifal-

mg.edu.br/revistas/index.php/cei/article/viewFile /301/pdf. ISSN:2359-6252

23- Campos GWS. SUS: O que e como fazer? Cienc Saude Coletiva 2018;23(6):1707-17. DOI: 10.1590/1413-81232018236.05582018
24- Maffesoli M. Saturação. São Paulo: Iluminuras; 2010.

25- Paim JS. Sistema Único de Saúde (SUS) aos 30 anos. Cienc Saude Coletiva 2018;23(6):1723-8. DOI: 10.1590/1413-81232018236.09172018

Nota: Este estudo foi financiado com bolsa PIBIC/CNPq, pelo Edital no 001/2015/PROPE, Programa Institucional de Bolsas de Iniciação Científica - PIBIC/CNPq/Universidade Federal de São João del-Rei.

Recebido em: 08/11/20

Aprovado em: 27/04/20

Endereço de correspondência:

Universidade Federal de São João del-Rei, Campus CentroOeste. Rua Sebastião Gonçalves Coelho, 400. Bairro Chanadour. Bloco A, sala 207. Divinópolis, Minas Gerais, Brasil. 35.501-296.

e-mail: selmaviegas@ufsj.edu.br 